\title{
Renovação do Serviço Social no Brasil e desafios contemporâneos*
}

\author{
Renewal of Social Work in Brazil \\ and contemporary challenges
}

\author{
Marilda Villela Iamamoto ${ }^{a}$ \\ (D) http://orcid.org/0000-0002-4838-1290
}

\begin{abstract}
Resumo: $\mathrm{O}$ texto reconstitui a história e memória no III Congresso Brasileiro de Assistentes Sociais, identificado como "Congresso da Virada". No atual contexto de crise, desigualdades e resistências são apresentados desafios na preservação de conquistas do Serviço Social no país nos últimos quarenta anos.

Palavras-chave: Fundamentos do Serviço Social. Serviço Social na América Latina. III Congresso Brasileiro de Assistentes Sociais.
\end{abstract}

\begin{abstract}
The text reconstructs the history and memory in the III Brazilian Congress of Social Workers, identified as "Virada Congress". In the current context of crisis, inequalities and resistance are presented challenges in the preservation of achievements of Social Service in the country in the last 40 years.
\end{abstract}

Keywords: Foundations of Social Work. Social Work in Latin America. III Brazilian Congress of Social Workers.

*Conferência proferida no 12 Seminário Anual de Serviço Social — Renovação e os 40 anos do Congresso da "Virada" no Serviço Social brasileiro. Memória, história e desafios contemporâneos, em 6 de maio de 2019, Tuca-PUC-SP, promovido pela Cortez Editora. Em 1979 nesse mesmo congresso é lançada a revista Serviço Social \& Sociedade, atualmente na plataforma Scielo, com classificação máxima na Capes e 139 números ininterruptos: um ícone editorial do Serviço Social no Brasil.

aUniversidade Federal de Juiz de Fora (UFJF), São Pedro/MG, Brasil.

Recebido: 16/5/2019 - Aprovado: 27/5/2019 


\section{Introdução}

V

ivemos tempos de obscurantismo e profunda regressão conservadora em favor dos interesses do grande capital produtivo e das finanças. Eles permeiam decisões de um Poder Executivo militarizado, que confronta valores democráticos e propõe a eliminação de direitos conquistados (Yazbek, 2018). Tempo de radical privatização, que destrói direitos trabalhistas, a Previdência Social, a universidade pública e o ensino superior federal público, pressionando sua privatização com o contingenciamento total ou parcial de verbas. Censura-se a universidade pública, as áreas de Filosofia e Sociologia são desqualificadas, e respeitáveis universidades brasileiras sofrem ameaças por supostas "balbúrdias", a que são reduzidas manifestações críticas à ordem instituída. Ante reações da comunidade acadêmica e da imprensa, o contingenciamento se universaliza ao conjunto da educação pública. As universidades sofrem um contingenciamento de $30 \%$ de receitas, além de expressivas restrições de recursos no ensino técnico e no Fundo Nacional da Educação.

Elucidar as "constelações que ligam o presente e o passado" é um movimento fundamental tanto para compreender o passado recente quanto o ineditismo das atuais condições históricas; e para recriar, no tempo presente, a práxis de enfrentamento às ameaças aos direitos civis, políticos e sociais, aos direitos humanos, à razão crítica, à liberdade de pensamento e de informação, à vida universitária em suas funções precípuas: ensino, pesquisa e extensão. Esta exposição pretende situar o Serviço Social na história sob ao ângulo das relações entre as classes, suas tensões e relações com o Estado, privilegiando o "ponto de vista dos vencidos" ou "dos de baixo", o que implica o reconhecimento do conflito de classes em suas dimensões materiais e espirituais, assim como o chamamento à resistência coletiva (Lowy, 2005).

Assistentes sociais brasileiros se posicionam publicamente no campo da resistência política na cena pública (CFESS, 2018; Abepss, 2018) em aliança com os segmentos de trabalhadores cujos interesses têm sido severamente atingidos pelo poder político e econômico. É como parte dessa 
resistência que pensamos o Serviço Social nesses tempos sombrios e os desafios prático-profissionais para alimentar a resistência.

A exposição aborda: 1) História e memória no III Congresso Brasileiro de Assistentes Sociais (CBAS). 2) História e desafios contemporâneos; 3) Conclusões.

\section{História e memória do III CBAS: resistência e renovação}

No nível do senso comum vem sendo difundida uma visão mágica do III CBAS: enredado em si mesmo, desvinculado da história socioprofissional e das articulações no Serviço Social latino-americano para sua viabilização.

Esse congresso é um marco simbólico na recusa do conservadorismo de origem no Serviço Social brasileiro em favor de sua renovação histórico-crítica, ao associar-se aos interesses e necessidades dos trabalhadores em luta pela democracia. Contestam-se propostas exógenas à realidade latino-americana e anuncia-se "a virada" dos compromissos políticos com as classes dominantes e o poder político, que presidiram a institucionalização e o desenvolvimento do Serviço Social no Brasil. Esse Congresso foi a primeira e tardia manifestação massiva da categoria dos assistentes sociais contra a ditadura militar-empresarial e o poder de classe que a sustentou.

A "virada" expressa a sintonia do Serviço Social brasileiro com as mobilizações de trabalhadores e entidades combativas da sociedade civil, numa aproximação com as lutas, organizações e movimentos sociais que portam a defesa dos direitos, interesses e projetos societários das classes subalternas - na criação de forças de resistência à ditadura do grande capital (Ianni, 1981) e no apoio ao processo de construção democrática. Dentre essas forças podem ser citadas (Alves, 1984): a) a Igreja Católica, representada na CNBB, cuja ala mais progressista é sensível à "Teologia da Libertação" - forte aliada na defesa dos direitos humanos 
e na denúncia da violência de Estado junto aos presos políticos. As Comunidades Eclesiais de Base (CEBS) marcam presença nas periferias, nas favelas, junto aos migrantes, aos camponeses e assalariados rurais, aos detentos, negros, índios e trabalhadores urbanos; b) as Associações de Moradores de Favelas ou Associações Comunitárias na luta por melhorias de condições de vida nos bairros e favelas, pressionam o poder público; c) a Ordem dos Advogados do Brasil (OAB) defende presos políticos e denuncia prisões arbitrárias, tornando-se destacada porta-voz da oposição; d) a Associação Brasileira de Imprensa (ABI) combate a censura de imprensa no teatro, na literatura, no cinema, na música, livros, revista e jornais; e) os estudantes universitários, sob a liderança da União Nacional dos Estudantes (UNE), realizam grandes manifestações e passeatas; f) o movimento sindical urbano e rural reage ao controle do Ministério do Trabalho sobre os sindicatos, defende a revogação da política de controle salarial e o reconhecimento do direito de greve, a autonomia sindical e as negociações coletivas: g) a reforma política de 1979 faz emergir novos partidos políticos. O Partido dos Trabalhadores, criado em 1980, passa a canalizar as reivindicações de diferentes movimentos populares.

É a existência dessas forças políticas que torna possível a contestação, expressa massivamente pelos assistentes sociais brasileiros no III CBAS, aos representantes do poder instituído em favor dos movimentos de trabalhadores, na defesa de eleições diretas e da democracia. A classe trabalhadora havia descoberto o seu poder, mantendo fortes vínculos entre lideranças e bases, e os assistentes sociais são parte desse processo.

As forças acadêmico-profissionais acumuladas pelo Serviço Social latino-americano e assistentes brasileiros são decisivas nessa "virada" do Serviço Social. Elas remontam ao movimento de reconceituação do Serviço Social (1965 e 1975), que cria bases materiais, intelectuais e políticas à sua renovação. Recusa-se o assistencialismo e a benemerência, questiona-se os fundamentos positivistas da tríade do Social Work norte-americano: o Serviço Social de casos, o Serviço Social de grupo e a organização/desenvolvimento de comunidade difundida por ideólogos de organismos internacionais durante a Guerra Fria. Busca-se um Serviço 
Social latino-americano fundado nas particularidades da formação histórica da América Latina e do Caribe, denunciando as relações de dependência ante os EUA.

O movimento de reconceituação foi impulsionado pela efervescência de lutas sociais - em particular a experiência cubana de 1959 -, que se refratam na universidade, nas ciências sociais, na Igreja, nos movimentos estudantis, no teatro, no Cinema Novo e na arte em geral. Esse movimento desencadeia-se no I Seminário de Serviço Social face às mudanças sociais na América Latina, em 1965, em Porto Alegre (RS), primeiro marco público da busca de um Serviço Social latino-americano. Denuncia-se a importação de parâmetros profissionais, o capitalismo dependente e o imperialismo norte-americano, num contexto político-cultural marcado pela vitória dos revolucionários da Sierra Maestra sobre Havana, das lutas estudantis de 1968, da abertura da Igreja Católica com o Concílio Ecumênico do papa João XXIII e da Teologia da Libertação. Esse primeiro seminário desdobrou-se em seis outros subsequentes, contribuindo para a maior organicidade do Serviço Social no continente: em Montevidéu, Uruguai (1966), em Concepción, Chile (1969), em Cochabamba, Bolívia (1970), e novamente em Porto Alegre, Brasil (1972).

Forças profissionais então hegemônicas no Serviço Social brasileiro reagem ao movimento desencadeado no Cone Sul. A hipótese é que os seminários de teorização do Serviço Social — especialmente os de Araxá (1967) e o de Teresópolis (1975) —, iniciativas voltadas para o aperfeiçoamento e a modernização do Serviço Social "tradicional", são uma resposta às articulações progressistas do Serviço Social no Cone Sul. Tais iniciativas, promovidos pelo Centro Brasileiro de Intercâmbio em Serviços Sociais (CBCISS,) são expressões da luta pela manutenção do poder e pela hegemonia por parte de orientações conservadoras e modernizantes no cenário do Serviço Social brasileiro (Aquino, Silva e Vieira, 2017). Os citados seminários são construídos em clara disputa com as orientações profissionais emergentes nos países de língua hispânica, configurando o que Aquin (2005) denomina de uma "reconceituação conservadora". Busca-se repensar o Serviço Social na perspectiva do "desenvolvimento", 
voltado ao aperfeiçoamento técnico para a implementação de um conjunto de programas sociais compensatórios da repressão, do arrocho salarial e da desmobilização política, que convivem com a expansão do braço repressivo do Estado ditatorial.

A Escola de Serviço Social da Universidade Católica de Minas Gerais (ESS/UCMG), ${ }^{1}$ integrada aos rumos do movimento de reconceituação latino-americano nos países de língua espanhola, constrói um projeto acadêmico que abrange a formação teórico-prática e o exercício profissional. Inscrita na região ferrífera e no cinturão industrial e operário de Belo Horizonte, as forças políticas aí presentes, com refrações no movimento estudantil (Batistoni, 2017), balizam também a experiência da ESS/UCMG. O conhecido "Método BH" é uma das expressões dessa experiência ao lado da proposta de formação acadêmica, que confrontam linhas teóricas dominantes na academia e nas entidades da categoria, como Associação Brasileira de Ensino em Serviço Social (Abess), o Conselho Federal de Assistentes Sociais e respectivos Conselhos Regionais (CFAS-Cras).

Nesse período ocorre na América Latina, uma (re)criação de entidades de Serviço Social: o Centro Latinoamericano de Trabajo Social (Celats), organismo acadêmico da Associación Latinoamericana de Escuelas de Trabajo Social (Alaets). Em 1976, o Celats foi reconhecido pelo governo peruano como organismo de cooperação técnica internacional. A Alaets, criada em 1965 no V Congresso Panamericano de Serviço Social da OEA, tem sua refundação política em Quito (Equador), em 1971, redirecionada aos dilemas latino-americanos, com independência do Serviço Social norte-americano e de organismos internacionais.

O movimento de reconceituação (Alayón, 1976 e 2005) expressa um amplo questionamento da profissão de Serviço Social (finalidades, fundamentos, compromissos éticos e políticos, procedimentos operativos e formação acadêmica), dotado de várias vertentes e com nítidas

1 Para uma análise global da experiência do grupo de Belo Horizonte, ver os seguintes documentos elaborados entre 1971 e 1974: "A prática como fonte de teoria" (1971); "Uma proposta de reestruturação da formação profissional”, publicados em Quiroga (1973a e1973b, respectivamente). 
particularidades nacionais que reclamam pesquisa. ${ }^{2}$ Mas sua unidade assentava-se na busca de construção de um Serviço Social latino-americano: na recusa da importação de teorias e métodos alheios à nossa história, na afirmação do compromisso com as lutas dos "oprimidos" pela "transformação social" e no propósito de atribuir um caráter científico às atividades profissionais. Denunciava-se a pretensa neutralidade político-ideológica, a restrição dos efeitos de suas atividades aprisionadas em microespaços sociais e a debilidade teórica no universo profissional. Os assistentes sociais assumem o desafio de contribuir na organização, capacitação e conscientização dos diversos segmentos trabalhadores e "marginalizados" na região.

De base teórica e metodológica eclética, esse movimento foi inicialmente polarizado pelas teorias desenvolvimentistas. Várias perspectivas críticas à ordem instituída passam a incidir no Serviço Social latino-americano: expressões políticas do marxismo na América Latina (Guevara, Fidel Castro, Camilo Torres, entre outros), a Teologia da Libertação, a Revolução Cultural chinesa, a experiência da União Soviética, o ideário da social-democracia alemã, a educação para a liberdade proposta por Paulo Freire aliada a experiências de educação popular e investigação-ação (Falls Borda). Somam-se a esses, movimentos contestatórios e expressões culturais de camponeses, trabalhadores industriais, indígenas, estudantis, de mulheres, negros e moradores das periferias urbanas. Mas esse movimento representou as primeiras aproximações do Serviço Social à diversificada tradição marxista. Ela foi apoiada em manuais de divulgação do marxismo-leninismo, em textos maoístas, no estruturalismo francês de Althusser, dentre outros.

\footnotetext{
2 A pesquisa O Movimento de Reconceituação do Serviço Social na América Latina (Argentina, Brasil, Chile e Colômbia): Determinantes históricos, interlocuções internacionais e memória (1960-1980), por mim coordenada, juntamente com a dra. Claudia Mônica dos Santos (UFJF), expressa uma iniciativa nessa direção, constituindo uma rede internacional de pesquisadores em fundamentos do Serviço Social. Dados relativos ao Celats são parte do subprojeto A Pesquisa Acadêmica no Centro Latinoamericano de Trabajo Social — Celats (1960-1980), sob a coordenação Raichelis (PUC-SP).
} 
Dentre os eixos de preocupações fundamentais do movimento de reconceituação podem ser salientados: o reconhecimento e a busca de compreensão dos rumos peculiares do desenvolvimento latino-americano; a criação de um projeto profissional abrangente, atento às características latino-americanas, em contraposição ao tradicionalismo; a necessidade de atribuir um estatuto científico ao Serviço Social; a explícita politização da ação profissional, solidária com a libertação dos oprimidos e comprometida com a "transformação social". Tais preocupações canalizam-se para a reestruturação da formação profissional que articule ensino, pesquisa e prática profissional, exigindo da universidade o exercício da crítica e da produção criadora de conhecimento no estreitamento de seus vínculos com a sociedade (Iamamoto, 1998, p. 209). As unidades de ensino foram o locus principal, ainda que não exclusivo, desse movimento.

São essas bases que tornam possível a "virada" ocorrida no III CBAS. Dimensão importante nesse processo foi o suporte latino-americano na articulação e no financiamento das entidades sindicais e associações profissionais: a presença do Celats — à época sob a direção de Leila Lima Santos - e da Alaets, sob a liderança do gaúcho Seno Cornely.

Pesquisa exploratória sobre as organizações gremiais de Serviço Social na América Latina — incluindo o caso brasileiro - é realizada sob a coordenação de Roberto Rodriguez e Walter Tesch (Celats, 1977). Em 1978, sindicatos e associações de assistentes sociais alinhadas ao sindicalismo classista se reúnem por duas ocasiões em Minas Gerais, com o patrocínio do Celats (Pinheiro, 2012), voltadas para reativar o movimento sindical no âmbito do Serviço Social no país. Propõem uma pesquisa nacional sobre as condições de trabalho, salariais, carga horária de trabalho, pautando-se a luta pela jornada de trinta horas e pelo salário mínimo profissional com o piso de dez salários mínimos (Abramides, 2012, p.54). O II Encontro Nacional de Entidades Sindicais, em São Paulo, preparatório do III CBAS, já registra a presença de 22 entidades sindicais e pré-sindicais, oposições sindicais, associações profissionais e núcleos pró-associações. É criada a Comissão de Executiva Nacional de Entidades Sindicais e Pré-Sindicais - Ceneas (Abramides, 2012, p. 55; Abramides e Cabral, 1995). Decide-se 
disputar eleições para os CFAS-Cras e formula-se manifesto a ser distribuído no III CBAS. Essas entidades já se somavam às forças políticas de resistência à ditadura e pela anistia, aos movimentos dos trabalhadores e das periferias das grandes cidades contra a carestia.

0 “Congresso da Virada" revela a luta política e profissional pela hegemonia presente no Serviço Social brasileiro. No segundo dia do evento é feita uma assembleia paralela com a presença de cerca de seiscentos participantes, sob a direção das entidades sindicais, da qual emerge a moção de substituir a Comissão de Honra desse congresso. Ela era composta por autoridades da ditadura militar nos níveis federal, estadual e municipal, a saber: general João Figueiredo, presidente da República; Jair Soares, ministro da Previdência; Murilo Macedo, ministro do Trabalho; Paulo Maluf, governador de São Paulo; Antônio Salim Curiati, prefeito biônico de São Paulo. A proposta foi de uma nova comissão formada por trabalhadores demitidos e perseguidos pela repressão, pela Comissão de Anistia e Movimento contra a Carestia (Souza, 2012, p. 40). A mesa de encerramento foi formada por Lula da Silva, o maior representante dos sindicalistas, Luiza Erundina de Souza representante do Ceneas. Ali destacava-se uma faixa com os dizeres: "Por todos aqueles que lutaram e morreram pelas liberdades democráticas no país” (Perez, 2012, p. 90). Assim, o "Congresso da Virada" foi fruto de uma organização prévia com direção política na disputa pela hegemonia no decurso do III CBAS. As entidades sindicais enfrentam o legalismo, a burocratização e o conservadorismo político confrontam orientações oficiais do CFAS-Cras, sintonizadas com o governo ditatorial.

Em agosto de 1979 ocorre no Rio de Janeiro, I Encontro Nacional de Capacitação Continuada (Iamamoto, Carvalho e Lima, 1979), promovido pelo Celats, em cooperação com o Instituto Nacional de Cooperativas Habitacionais (Inocoop) e a Pontifícia Universidade Católica do Rio de Janeiro (PUC-RJ). Esse encontro adensa bases analíticas à preparação do Congresso da Virada, em uma explícita disputa teórica no Serviço Social brasileiro. $\mathrm{O}$ evento congrega representantes progressistas de faculdades, organismos e associações sindicais e entidades vinculadas ao trabalho 
de campo de treze estados brasileiros: São Paulo, Minas Gerais, Goiás, Mato Grosso, Bahia, Paraíba, Espírito Santo, Sergipe, Rio Grande do Norte, Maranhão, Paraná, Santa Catarina e Rio de Janeiro. Polarizam os debates os temas: a relação entre prática profissional, instituições e contexto social; a dimensão política da prática profissional e a organização profissional. O assistente social é reconhecido como trabalhador assalariado, funcionário de uma instituição, cuja ação condensa interesses de classe diferenciados. A resposta institucional às necessidades dos trabalhadores depende da dinâmica da luta dos grupos e do poder de negociação e pressão que a classe trabalhadora possa dispor em determinadas conjunturas. O Serviço Social é compreendido enquanto parte da prática social coletiva de classes e grupos sociais com interesses contraditórios que conformam a sociedade, tendendo a ser cooptado por aqueles que são dominantes. Daí deriva a necessária dimensão política da prática profissional: o assistente social atua em políticas públicas que traduzem intenções e interesses das classes fundamentais da sociedade e é por eles polarizada, afirmando-se a necessidade de opção em favor de interesses de uma das classes fundamentais. É constatado o precário nível organizativo da profissão e a necessidade de sua revitalização em uma conjuntura em que interesses imediatos da categoria se tornem convergentes aos dos amplos setores de trabalhadores e suas famílias, incentivando a participação conjunta em lutas reivindicatórias a partir dos locais de trabalho e na organização sindical. Vários depoimentos registram a participação direta dos assistentes sociais nas lutas e mobilizações dos setores populares, que se reconhecem como trabalhadores assalariados nas instituições em que trabalham, congregados em associações e sindicatos de assistentes sociais.

No período que antecede o Congresso da Virada, Celats e Alaets inauguram na América Latina e Caribe, no VII Seminário Latinoamericano da Alaets (1977), o debate sobre política social e Serviço Social, ${ }^{3}$ contribuindo

3 Esse debate tem continuidade nos dois seminários subsequentes: no VIII Seminário da Alaets em Guayaquil, no Simpósio de Playas (Equador) e no IX Seminário da Alaets em Caracas, em 
para o reconhecimento da dimensão política do trabalho do assistente social. A revista Acción Critica alimenta o debate da política social com textos pioneiros entre 1977 e 1985. Essa abordagem acompanha esforços desenvolvidos no Celats no sentido de situar o Serviço Social no âmbito das relações entre as classes e destas com o Estado, rompendo a análise isolada e endógena do exercício profissional. Na leitura da política social, o Estado expressa a condensação de forças sociais e, nesse sentido, as contradições das classes, não sendo instrumento exclusivo de realização dos interesses da burguesia, ainda que seja um Estado burguês. Assim, a dominação é contraditória em dupla dimensão: porque expressa alianças de classes ou frações dominantes que não são similares, refletindo seus conflitos e pressões permanentes; e, fundamentalmente, porque se o Estado exclui as chamadas classes dominadas, tem, em certa medida, que incorporar alguns de seus interesses, como um "pacto de dominação" (Kowarick, 1979). As políticas sociais traduzem sempre uma tensão contraditória entre os imperativos da reprodução do capital por um lado e, por outro, as necessidades da reprodução da força de trabalho, para o que os gastos públicos são fundamentais. Esse caráter contraditório do Estado e da política social, cujo chão é a sociedade de classes, estende-se também à análise da profissão.

Dentre as conquistas desse legado tem-se a ruptura de uma visão do Serviço Social, prisioneira de seus muros internos, apoiada na díade "homem-meio" e na relação "assistente social-cliente" voltada ao ajustamento do indivíduo à sociedade. A "prática" é desvinculada da trama social que cria sua necessidade e condiciona seus efeitos na sociedade. Os processos históricos, quando considerados, tendem a ser reduzidos a um "contexto", distinto da prática profissional, que a condicionaria "externamente". A "prática” - tida como uma relação singular entre o assistente social e o sujeito atendido individualmente, em grupo ou em

junho de 1979. Também no Encontro Prévio a Assembleia Geral Ordinária da Alaets realizada em junho de 1980, em São Paulo, o sociólogo peruano Jorge Parodi apresenta um balanço desse debate (Parodi, 1980). 
comunidades - é tratada desvinculada da "questão social" e das políticas sociais correspondentes. Nessa perspectiva, a formação profissional deveria privilegiar a construção de estratégias, técnicas e formação de habilidades - centrando-se no "como fazer" - a partir da justificativa de que o Serviço Social é uma "profissão voltada para a intervenção no social” visando a integração social, sob influxos liberais na compreensão e condução da "prática profissional". Esse caminho trilhado na história da profissão — que a reação conservadora busca reeditar no presente está fadado a criar um assistente social que aparentemente sabe fazer, mas não consegue explicar as razões, o conteúdo, a direção social e os efeitos de seu trabalho na sociedade. Corre-se o perigo de ele ser reduzido a mero "técnico", delegando a outros a tarefa de pensar a sociedade. O resultado é um profissional mistificado e da mistificação, dotado de frágil identidade com a profissão.

A contrapartida é outra leitura do Serviço Social no âmbito das relações entre as classes e destas com o Estado no enfrentamento das desigualdades sociais por meio das políticas públicas e na atuação junto aos movimentos sociais.

\section{História e desafios contemporâneos: resistência e preservação de conquistas}

Na perspectiva da preservação de conquistas do Serviço Social dos últimos quarenta anos, há que reconhecer que o Serviço Social no Brasil tem vivido um duplo e contraditório movimento: o mais representativo foi o processo de ruptura teórica e política com o lastro conservador de suas origens; em sinal contrário, verificou-se o revigoramento de uma reação (neo)conservadora aberta elou disfarçada em aparências que a dissimulam, apoiada na negação da sociedade de classes (Netto, 1996).

O Serviço Social brasileiro, nas últimas décadas, no lastro das lutas sociais contra a ditadura (1964-85) e pela defesa do Estado de direito, 
fez um radical giro na sua dimensão ética e política. Sua base normativa é formada pela Lei da Regulamentação da Profissão (1993), pelas Diretrizes Curriculares Nacionais para o ensino de graduação (1996) e pelo Código de Ética do Assistente Social (1993), pilares do projeto profissional brasileiro. Ele foi alimentado teoricamente pela tradição marxista - no diálogo com outras matrizes analíticas - e politicamente pela aproximação às forças vivas que movem a história: as lutas, organizações e movimentos sociais. Seu núcleo central é a compreensão da história a partir das classes sociais, conflitos, o reconhecimento da centralidade do trabalho e dos trabalhadores A partir dos anos 1980 depura-se a aproximação na área de Serviço Social aos textos originais de Marx, em especial à sua Crítica da economia política. Ao mesmo tempo, diversifica-se ao debate no interior da tradição marxista, ${ }^{4}$ rompendo barreiras disciplinares.

O Serviço Social é apreendido como uma especialização do trabalho da sociedade, inscrito na divisão social e técnica do trabalho. O "significado sócio-histórico e ideopolítico do Serviço Social inscreve-se no conjunto das práticas sociais acionado pelas classes e mediadas pelo Estado em face das 'sequelas' da questão social” (Abepss/Cedepss, 1996). O exercício profissional é necessariamente polarizado pela trama de relações e interesses entre as classes sociais. Ele participa tanto dos mecanismos de exploração e dominação, quanto, ao mesmo tempo e pela mesma atividade, de respostas institucionais às necessidades de sobrevivência das classes trabalhadoras e da reprodução do antagonismo dos interesses sociais (Iamamoto e Carvalho, 1982). Como a sociedade é portadora de projetos sociais distintos — projeto de classes para a sociedade —, tem-se um terreno histórico aberto à construção de projetos profissionais também diversos, indissociáveis de projetos mais amplos para a sociedade.

4 Debate-se o poder político com A. Gramsci, a ontologia do ser social e a estética com G. Lukács; a Escola de Frankfurt e o debate sobre a cultura; I. Mèszáros, Eric Hobsbawm, E. P. Thompson na leitura da história; David Harvey na geografia, Ernest Mandel no debate do capitalismo tardio, dentre outros. 
É essa presença de forças sociais e políticas reais - e não mera ilusão - que permite à categoria profissional estabelecer estratégias político-profissionais no sentido de reforçar interesses das classes subalternas, alvo prioritário das ações profissionais.

A orientação histórico-crítica do Serviço Social brasileiro é inédita na literatura mundial do Serviço Social. Ela vem permitindo, no país, uma série de conquistas coletivas, dentre as quais pode-se citar: a) o vínculo da imagem do Serviço Social com os direitos na recusa da benemerência; b) a ampliação dos espaços ocupacionais na órbita das políticas públicas nos niveis federal, estadual e municipal, alargando o mercado de trabalho especializado; c) a ampliação das competências do(a) assistente social para além da execução de políticas, incluindo sua formulação, avaliação e financiamento; d) a consolidação da formação pós-graduada (mestrado e doutorado) na universidade pública, o desenvolvimento de cursos de especialização nas áreas mais representativas do mercado de trabalho aliada à qualificação das graduações com base em diretrizes curriculares nacionais da Associação Brasileira de Ensino e Pesquisa em Serviço Social (Abepss); e) a consideração dos dilemas históricos da formação social no Brasil em suas particularidades, propiciando o conhecimento das expressões da "questão social" e dos sujeitos que vivenciam; f) a defesa das condições de trabalho, do piso salarial e da jornada de trinta horas estabelecida por lei federal; g) o debate ético em profundidade e na defesa do princípios e valores éticos que guiam o Serviço Social brasileiro e aderido no cotidiano de trabalho; $h$ ) os estudos de competências e atribuições profissionais (arts. 4 e 5 da Lei da Regulamentação da Profissão) nas áreas de assistência, saúde, educação, sociojurídica, dentre outras; i) entidades nacionais representativas e dotadas de capilaridade nacional: a Abepss e o conjunto do Conselho Federal de Serviço Social e conselhos regionais (CFESS-Cress) e a Executiva Nacional de Estudantes de Serviço Social (Enesso); j) a preservação da capacidade de indignar-se ante as injustiças, discriminações no aprendizado da luta coletiva na defesa da grande política. 
A proposta restauradora e conservadora parte de uma idealização do passado nos moldes do Social Worker (Serviço Social de casos, Serviço Social de grupo e desenvolvimento de comunidade), identificado como modelo de profissionalização. Supostamente neutro e apolítico, é erigido como referência de competência técnica na "intervenção". Em nome do Serviço Social internacional reclama-se o retorno a autores representativos do Social Work, evidente no Serviço Social clínico. A superficialidade na abordagem dos fundamentos do Serviço Social mostra-se incapaz de responder ao debate teórico rigoroso. Sob o signo de "politização à esquerda" ou "militantismo" - tidos como causa de suposta "desprofissionalização" do Serviço Social —, reitera-se a velha crítica conservadora à reconceituação. As circunstâncias sociais e históricas em que se inscreve o trabalho profissional são silenciadas e a politização à direita e a militância religiosa presentes não são reconhecidas como tais. A crítica ideológica é direcionada exclusivamente às propostas “de esquerda”. Esse caldo cultural dispõe de aderente terreno societário à sua difusão ante a crise econômica e o desmonte do Estado brasileiro e de suas políticas públicas, impulsionando a defesa das conquistas do Serviço Social nas últimas quatro décadas.

O presente retrocesso político-institucional do país ocorre no lastro da crise financeira desencadeada na Europa em 2008 com a estagnação da economia mundial. Ela é tributária de políticas governamentais favorecedoras da esfera financeira e do grande capital produtivo - das instituições e mercados financeiros e das empresas multinacionais -, enquanto um conjunto de forças que captura os Estados nacionais e redimensiona as políticas públicas sob inspiração neoliberal. Como sustenta Salama (1999), a lógica financeira do regime de acumulação tende a provocar crises que se projetam no mundo gerando recessão. A volatividade do crescimento redunda em maior concentração de renda, da propriedade e aumento da pobreza, não apenas nas periferias dos centros mundiais, pois atinge os recônditos mais sagrados do capitalismo mundial. Cresce a necessidade de financiamento externo e, com ela, a dívida 
interna e externa, os serviços da dívida — os pagamentos de juros -, ampliando o déficit comercial. As exigências do pagamento dos serviços da dívida, aliada às elevadas taxas de juros, geram escassez de recursos para investimento e custeio. Favorecem os investimentos especulativos em detrimento da produção, o que se encontra na raiz da redução dos níveis de emprego, do agravamento das desigualdades e da regressão das políticas sociais públicas.

As desigualdades são reforçadas com políticas tributárias regressivas, em que a arrecadação fiscal tem uma incidência proporcionalmente maior sobre as menores rendas, penalizando os contribuintes de menor poder aquisitivo (Boschetti e Salvador, 2006; Behring, 2010, Boschetti et al. 2010). As políticas liberais para enfrentar a crise buscam restaurar e consolidar o poder do capital, privatizando lucros e socializando custos (Harvey, 2011). Alarga-se a distância entre ricos e pobres, radicalizando desigualdades sociais e as lutas contra elas. Reativa-se as intolerâncias política, religiosa, racial e de gênero, os xenofobismos e a pilhagem de recursos naturais do planeta: da água, do ar e das florestas.

Características persistentes da "revolução burguesa" no Brasil (Fernandes, 1975) - fruto de uma burguesia nacional subordinada e associada aos núcleos imperialistas - são recicladas sob a prevalência do capital que rende juros associado ao grande capital produtivo: o reforço da heteronomia ou dependência externa e a ampliação das desigualdades internas, enquanto estratégias de domínio de classe. Tais características se atualizam nas atuais condições políticas do país: a forte presença do poder militar no controle do governo; a estreita articulação com a geopolítica norte-americana contra as forças progressistas na América Latina; o ultraneoliberalismo na condução de políticas governamentais; a criminalização e a eliminação das forças de oposição, o intenso investimento ideológico na adesão ao poder instituído por meio da religião de raiz protestante e de recursos midiáticos enquanto estratégias de legitimação política, em detrimento do debate e defesa de projetos para 
o Brasil. As forças de resistência sofrem com a recessão econômica, a repressão e a criminalização dos movimentos sociais.

Segundo a Cepal $^{5}$ (2016, 2018), a América Latina e o Caribe continuam sendo as regiões mais desiguais do mundo, ultrapassando a África Subsaariana. Em 2017, ainda vivem em pobreza 184 milhões de latino-americanos (30,2\% da população), dos quais 62 milhões $(10,25 \%$ da população) em situação de extrema pobreza, maior contingente já registrado desde 2008. A pobreza afeta de maneira desproporcional as crianças, adolescentes, jovens, mulheres, a população nas áreas rurais, indígenas e afrodescendentes, havendo ainda a interveniência da identidade sexual.

Verifica-se uma expansão do mercado de trabalho predominantemente informal, com crescimento no setor de serviços de baixa produtividade e altas taxas de informalidade, característica central na América Latina e no Caribe (PNUD, 2016; Cepal, 2018). Ele também atinge os assistentes sociais enquanto trabalhadores assalariados. A informalidade implica falta de acesso à: seguridade social, jornadas de trabalho definidas (com descanso semanal e férias remuneradas), aposentadoria e pensão, seguro-desemprego, seguro contra acidentes e doenças ocupacionais, proteção a paternidade e maternidade, bem como outros direitos previstos na legislação trabalhista. Em média, cerca de $40 \%$ a população ocupada na informalidade tem rendimento inferior ao salário mínimo.

Mas existem formas de articulação coletivas expressas em movimentos de trabalhadores (rurais e urbanos) e de novos sujeitos coletivos (Gramsci, 1981, 1979, 2001) presentes na luta contra as desigualdades

5 A Comissão Econômica das Nações Unidas para América Latina (Cepal) nos documentos Panorama Social da América Latina (2016 e 2018), considera a desigualdade um fenômeno multidimensional, englobando: a distribuição de renda, a estrutura de classe expressa na propriedade de ativos físicos e financeiros, o gasto público e social, a estrutura etária, o tempo, a presença das populações afrodescendentes, além da convivência com experiências de redução da pobreza. 
na defesa dos direitos humanos: a mobilização estudantil na defesa da educação pública; o movimento dos sem-teto e dos trabalhadores sem-terra; o movimento das nações indígenas pela preservação de seu patrimônio material e cultural; as lutas das mulheres contra a opressão, o feminicídio, o assédio e pela legalização do aborto; as manifestações coletivas contra o desmonte da Previdência Social; as lutas dos afrodescendentes por direitos e contra o preconceito; da juventude trabalhadora da periferia das grandes cidades contra o genocídio de jovens, negros, pobres das periferias urbanas; a luta contra a fobia LGBTT e contra todas as formas de racismo.

Amplia-se a criminalização das classes subalternas - especialmente de jovens, trabalhadores, negros - e dos seus movimentos e expressões coletivas. Aproximadamente 130 milhões de afrodescendentes vivem na América Latina (21\% da população), sendo 91\% do total regional concentrados no Brasil e em Cuba (Cepal, 2016). Nos ataques à classe trabalhadora, mulheres e jovens negras(os) são as principais vítimas da cultura que fomenta o ódio contra as diferenças de cor/raça, sexualidades, territórios. No Brasil, a fobia LGBTT matou, em 2017, 445 lésbicas, gays, bissexuais, travestis e transsexuais (LGBTT), conforme denúncia da Abepss (2017).

Esse panorama nos convoca a acumular forças políticas e forjar a resistência na defesa da democracia, dos direitos humanos e da justiça social, no horizonte da emancipação de cada um e de todos os indivíduos sociais.

\section{Conclusões}

Reconhecendo a diversidade de propostas em disputa na arena do Serviço Social brasileiro, o desafio é manter com garra a luta pela hegemonia no Serviço Social como profissão e como disciplina científica. Há que romper com as teias da pequena política, em termos gramscianos, 
como já nos alertou Coutinho (2000): a política deixa de ser pensada como "arena de luta entre propostas de sociedade", passando a ser concebida como "simples administração do existente", alheia à vida cotidiana dos indivíduos. O burocratismo faz renascer o devotamento à técnica, ao "como fazer" em nome da eficiência da "prática", que é mistificada, favorecendo o obscurecimento ideológico do grande jogo político que subjaz à rotina da burocracia estatal.

Importa reforçar alianças com outros profissionais, com entidades de representação coletivas, com fóruns de representação de políticas, de articulação de trabalhadores e movimentos sociais, de modo que suas necessidades e interesses possam adquirir visibilidade e ser reconhecidos na cena pública. "Não soltar a mão de ninguém" para preservar a força de nossa resistência coletiva. Ela é potenciada na aproximação às lutas dos trabalhadores e movimentos sociais na defesa dos direitos, interesses e projetos societários das classes subalternas, expressando suas necessidades e aspirações na cena pública. Esses tempos adversos exigem dos assistentes sociais recriar seu trabalho considerando tanto sua contribuição na reprodução material dos sujeitos, expressa na prestação de serviços sociais de qualidade a partir de políticas públicas, quanto sua dimensão educativa que incide na cultura das classes subalternas: nas maneiras de ver, viver e sentir a vida, fortalecendo a dimensão coletiva das lutas sociais.

A prof. Maria Inês Bravo, em entrevista no dia 1 de maio ao CFESS (2019) sintetiza chaves de dilemas e desafios. Diz ela:

Esta conjuntura afeta os/as assistentes sociais nas condições de trabalho: pressiona baixos salários, instabilidade e desemprego; afeta as atribuições profissionais com a demanda de empregadores na burocratização das ações, o desvio de funções, na solicitação de apassivamento dos sujeitos com quem trabalhamos. Desafia o trabalho cotidiano; o efetivo trabalho socioeducativo, reflexivo com indivíduos e grupos refletindo o impacto das contrarreformas afetam suas condições de vida e de trabalho; o estímulo à organização e participação dos sujeitos em fóruns, conselhos de direitos 
e de políticas e conferências pressionando para que se realizem; a organização e participação junto com a classe trabalhadora na mudança dessas condições perversas que estamos vivendo.

Um desafio é romper com os burocratismos, com a naturalização das rotinas de trabalho e atitudes passivas acolhedoras de ordens. E "ir onde o povo está", viver com ele suas paixões passíveis de serem por eles traduzidas em projetos de ação coletiva, recriando estratégias, reinventando formas culturais coletivas de organização política.

A defesa do Serviço Social enraizado nas particularidades e dilemas de Nuestra América é hoje abraçado por nossas entidades acadêmicas e gremiais, o que amplia nossa força: a Alaeits, a Federação Internacional de Assistentes Sociais (Fits) - região da América Latina e Caribe - e o Comitê Latino-Americano e Caribenho de Organizações Profissionais de Serviço Social (Colacats).

Apesar dos tempos sombrios e por meio deles "chegam aromas de amanhã em mim"

Manuel de Barros

\section{Referências}

ABESS/CEPESS. Diretrizes gerais para o curso de Serviço Social (com base no currículo mínimo aprovado em Assembleia Geral Extraordinária de 8 de novembro de 1996). Caderno Abess, São Paulo, n. 7, 1997.

ABRAMIDES, M. B. C. Mesa de depoimentos históricos. In: CFESS. Seminário Nacional do Congresso da Virada. 30 anos. 1979-2009. Brasília: CFESS, 2012. p. 51-60.

; CABRAL, S. O novo sindicalismo e o Serviço Social. São Paulo: Cortez, 1995.

ALAYÓN, N. (Org.). Trabajo social latino-americano. A 40 años de la reconceptualización. Buenos Aires: Espacio Ed., 2005.

. Desafio al Servicio Social. Buenos Aires: Humanitas, 1976.

ALVES, M. H. Estado e oposição no Brasil (1964-1984). Petrópolis: Vozes, 1984. 
AQUIN, N. Reconceptualización: un trabajo social alternativo o una alternativa al Trabajo Social? Serviço Social \& Sociedade, São Paulo, n. 84, p. 48-65, 2005.

AQUINO, I. G. de C.; SILVA, A. P. R.; VIEIRA, P. L. C. O Movimento de Reconceituação na América Latina e suas expressões internacionais: análise crítica da participação e contribuição do CBCISS. Em Pauta, Rio de Janeiro, n. 40, v. 15, p. 151-165, 2. semestre 2017.

BATISTONI, R. O Movimento de Reconceituação no Brasil: o projeto profissional da Escola de Serviço Social da Universidade Católica de Minas Gerais (1964-1980). Em Pauta, Rio de Janeiro, n. 40, v. 15, p. 136-150, 2. semestre 2017.

BEHRING, E. Crise do capital, fundo público e valor. In: BOSCHETTI, I. et al. Capitalismo em crise: política social e direitos. São Paulo: Cortez, 2010. p. 13-34.

BOSCHETTI, I. et al. Capitalismo em crise: política social e direitos. São Paulo: Cortez, 2010. p. 13-34.

BOSCHETTI, I.; SALVADOR, E. Orçamento da seguridade social e política econômica. Perversa alquimia. Serviço Social \& Sociedade, São Paulo, n. 87, p. 25-57, 2006.

CELATS. Poblacional y gremial: dos investigaciones Celats. Accion Crítica, Lima, n. 2, p. 69-73, jul. 1977.

COUTINHO, C. N. Contra a corrente: ensaios sobre democracia e socialismo. São Paulo: Cortez, 2000.

FERNANDES, F. A revolução burguesa no Brasil. Ensaio de interpretação sociológica. São Paulo: Zahar, 1975.

GRAMSCI, A. Maquiavel, a política e o Estado moderno. 3. ed. Rio de Janeiro: Civilização Brasileira, 1979.

A concepção dialética da história. Rio de Janeiro: Paz e Terra, 1981.

. Cadernos do Cárcere. Rio de Janeiro: Civilização Brasileira, 2001.

HARVEY, D. O enigma do capital e as crises do capitalismo. Rio de Janeiro: Boitempo, 2011.

IAMAMOTO, M. V. O debate contemporâneo da reconceituação do Serviço Social: ampliação e aprofundamento do marxismo. In: Serviço Social na contemporaneidade: trabalho e formação profissional. São Paulo: Cortez, 1998. p. 201-250.

; CARVALHO, R. Relações sociais e Serviço Social no Brasil: esboço de uma interpretação histórico-sociológica. São Paulo: Cortez/Celats, 1982.

; ___ _ LIMA, L. Encuentro Nacional de Capacitación. Rio de Janeiro, Brasil. Acción Crítica n. 6. Lima: Celats/Alaets, p. 32-37, set. 1979.

IANNI, O. A ditadura do grande capital. Rio de Janeiro: Civilização Brasileira, 1981.

KOWARICK, L. Proceso del desarrollo del Estado en América Latina y políticas sociales. Acción Crítica, Costa Rica, n. 5, p. 25-31, abr. 1979.

LÖWY, M. Walter Benjamim: aviso de incêndio. São Paulo: Boitempo, 2005. 
NETTO, J. P. Transformações societárias e Serviço Social: notas para uma análise prospectiva da profissão no Brasil. Serviço Social \& Sociedade, São Paulo, n. 50, p. 87-132, 1996.

PARODI, J. Seminário Latinoamericano de Alaets Proceso de reflexión coletiva: La política social y los trabajadores sociales. Acción Crítica, Lima, n. 7, p. 51-58, jul. 1980.

PEREZ, M. C. V. Mesa de depoimentos históricos. In: CFESS. Seminário Nacional do Congresso da Virada. 30 anos. 1979-2009. Brasília: CFESS, 2012. p. 87-90.

PINHEIRO, M. Mesa de depoimentos históricos. In: CFESS. Seminário Nacional do Congresso da Virada. 30 anos. 1979-2009. Brasília: CFESS, 2012. p. 71-76.

QUIROGA, Consuelo (Org.). Compendio sobre la metodología del trabajo social. Buenos Aires: Ecro, 1973a.

. Compendio sobre la reestructuración de la carrera de trabajo social. Buenos Aires: Ecro, 1973b. p. 25-67.

SALAMA, P. Pobreza e exploração do trabalho na América Latina. São Paulo: Boitempo, 1999.

SOUZA, L. E. Mesa de depoimentos históricos. In: CFESS. Seminário Nacional do Congresso da Virada. 30 anos. 1979-2009. Brasília: CFESS, 2012. p. 39-46.

YAZBEK, M. C. Serviço Social e seu projeto ético-político em tempos de devastação: resistências, lutas e perspectivas (25 anos do Código de Ética). Vitória: Abepss/Enpess, 2018. (Não publicado)

\section{Fontes eletrônicas}

CFESS. Disponível em: http://www.cfess.org.br/arquivos/2018-ServicoSocialNoticia-Site. pdf. Acesso em: 15 maio 2018.

. Primeiro de maio: somos assistentes sociais, somos classe trabalhadora! Disponível em: http://www.cfess.org.br/visualizar/noticia/cod/1566. Acesso em: 1 maio 2019.

ABEPSS. Disponível em: http://www.abepss.org.br/noticias/somos-assistentes-sociais-prontos-para-existir-e-fazer-brotar-a-flor-viva-1917. Acesso em: 15 maio 2018.

CEPAL Panorama social para América Latina. 2016. Disponível em: https://www.cepal. org/pt-br/publicaciones/41738-panorama-social-america-latina-2016-documento-informativo. Acesso em: 25 maio 2018.

CEPAL Disponível em: http://agenciabrasil.ebc.com.br/internacional/noticia/2017-05/desigualdade-na-america-latina-segue-em-ritmo-muito-alto-diz-cepal. Acesso em: 15 maio 2018.

CEPAL. Panorama social para América Latina. 2018. Documento informativo. Disponível em: https://www.cepal.org/pt-br/publicaciones/44412-panorama-social-america-latina-2018-documento-informativo. Acesso em: 24 abr. 2019. 
PNUD. http://www.latinamerica.undp.org/content/rblac/es/home/presscenter/pressreleases/2016/06/14/reca-da-de-millones-de-latinoamericanos-a-la-pobreza-es-evitable-con-pol-ticas-publicas-de-nueva-generaci-n-pnud.html. Progreso multidimensional: bienestar más allá del ingresso. Acesso em: 28 maio 2018.

\section{Sobre a autora}

MaRilda Villela IAmamoto - Professora titular aposentada da Universidade Federal do Rio de Janeiro (UFRJ) e da Universidade Estadual do Rio de Janeiro (UERJ). Professora visitante no Programa de Pós-Graduação em Serviço Social da Universidade Federal de Juiz de Fora (UFJF). Pesquisadora do CNPq, bolsista produtividade nível $1 \mathrm{~A}$. Autora de livros na área de fundamentos do Serviço Social. E-mail: mviamamoto@uol.com.br 